\title{
Atrial Fibrillation Impairs the Diagnostic Performance of Cardiac Natriuretic Peptides in Dyspneic Patients
}

\section{Results From the BACH Study (Biomarkers in ACute Heart Failure)}

Mark Richards, MD, PHD, ${ }^{*} \dagger$ Salvatore Di Somma, MD, $\ddagger$ Christian Mueller, MD,,

Richard Nowak, MD, || W. Frank Peacock, MD, $\uparrow$ Piotr Ponikowski, MD, PHD,\#

Martin Mockel, MD, ${ }^{* *}$ Christopher Hogan, MD, †† Alan H. B. Wu, PHD, †† Paul Clopton, MS, $\S \S$

Gerasimos S. Filippatos, MD,||| Inder Anand, MD, DPHIL(OxON), Ф Leong Ng, MD,\#\#

Lori B. Daniels, MD, MAS, *** Sean-Xavier Neath, MD, PHD, ††† Kevin Shah, BS, $₫ \S \S$

Robert Christenson, PHD, $\dagger \dagger \dagger$ Oliver Hartmann, MSc, $+\ddagger \ddagger$ Stefan D. Anker, MD, PHD, ${ }^{* *} \S \S \S$

Alan Maisel, $\mathrm{MD}^{\text {**** }}$

Christchurch, New Zealand; Singapore; Rome, Italy; Basel, Switzerland; Detroit, Michigan; Cleveland, Ohio;

Wroclaw, Poland; Berlin, Germany; Richmond, Virginia; San Francisco and San Diego, California;

Minneapolis, Minnesota; Leicester, United Kingdom; and Baltimore, Maryland

Objectives

Background

Methods

Results

Conclusions
The purpose of this study was to assess the impact of atrial fibrillation (AF) on the performance of mid-region amino terminal pro-atrial natriuretic peptide (MR-proANP) in comparison with the B-type peptides (BNP and NT-proBNP) for diagnosis of acute heart failure (HF) in dyspneic patients.

The effects of AF on the diagnostic and prognostic performance of MR-proANP in comparison with the B type natriuretic peptides have not been previously reported.

A total of 1,445 patients attending the emergency department with acute dyspnea had measurements taken of MR-proANP, BNP, and NT-proBNP values on enrollment to the BACH trial and were grouped according to presence or absence of $A F$ and $H F$.

AF was present in 242 patients. Plasma concentrations of all three peptides were lowest in those with neither AF nor HF and $A F$ without $H F$ was associated with markedly increased levels $(p<0.00001)$. HF with or without AF was associated with a significant further increment $(p<0.00001$ for all three markers). Areas under receiver operator characteristic curves (AUCs) for discrimination of acute HF were similar and powerful for all peptides without AF (0.893 to 0.912 ; all $p<0.001$ ) with substantial and similar reductions $(0.701$ to 0.757$)$ in the presence of AF. All 3 peptides were independently prognostic but there was no interaction between any peptide and AF for prediction of all-cause mortality.

AF is associated with increased plasma natriuretic peptide (MR-proANP, BNP and NT-proBNP) levels in the absence of HF. The diagnostic performance of all three peptides is impaired by AF. This warrants consideration of adjusted peptide thresholds for diagnostic use in AF and mandates the continued search for markers free of confounding by AF. (J Am Coll Cardiol HF 2013;1:192-9) @ 2013 by the American College of Cardiology Foundation
Atrial fibrillation (AF) is the most common dysrhythmia among patients presenting to the emergency department (ED) (1-4). Age, hypertension, diabetes, and acute heart failure (HF) are risk factors associated with developing AF

From the *University of Otago, Christchurch, New Zealand; †National University Heart Centre, Singapore; $\ddagger$ Sant'Andrea Hospital, University La Sapienza, Rome, Italy; §University Hospital Basel, Basel, Switzerland; $\|$ Henry Ford Health System, Detroit, Michigan; $\uparrow$ The Cleveland Clinic, Cleveland, Ohio; \#Medical University, Faculty of Public Health, Wroclaw, Poland; **Charite, Campus Virchow-Klinikum,
(4-6). Patients with new onset or accelerated AF may complain of dyspnea, chest pain, palpitations, weakness, or

See page 213

Berlin, Germany; $\dagger$ Virginia Commonwealth University, Richmond, Virginia; $\ddagger \ddagger$ University of California San Francisco, California; $\S \S$ Veterans' Administration San Diego Healthcare System, San Diego, California; \|\| Athens University Hospital Attikon, Athens, Greece; đIVeterans' Administration Minneapolis, Minnesota; \#\#University of Leicester, Leicester, United Kingdom; **** University of California San 
syncope. AF may cause or complicate HF and establishing the presence or absence of $\mathrm{HF}$ in dyspneic patients with $\mathrm{AF}$ may be challenging. The $\mathrm{B}$ type cardiac peptides are established as aids to the diagnosis of $\mathrm{HF}$ in patients presenting to the $\mathrm{ED}$ with recent onset dyspnea $(7,8)$. $\mathrm{AF}$, a frequent comorbidity in $\mathrm{HF}$, disturbs plasma B-type natriuretic peptide (BNP) and amino terminal pro-B-type natriuretic peptide (NT-proBNP) (9-13) and may impair their performance in the diagnosis of $\operatorname{HF}(9,10)$.

The stable hormone fragment of atrial natriuretic peptide (MR-proANP) has similar utility in diagnosing $\mathrm{HF}$ as the $\mathrm{B}$ type peptides $(14,15)$. We assessed the effect of AF on the diagnostic performance of MR-proANP, in comparison to $\mathrm{BNP}$ and NT-proBNP, in patients enrolled in the $\mathrm{BACH}$ (Biomarkers in Acute Heart Failure) trial.

\section{Methods}

As previously described, the $\mathrm{BACH}$ trial was a prospective, 15-center international study of patients presenting to the ED with acute dyspnea (15). Results indicated noninferiority for MR-proANP for diagnosis of HF. Data for rhythm (according to electrocardiography [ECG] on recruitment; available in 1,445 cases), biomarkers (BNP, NT-proBNP and MR-proANP), and outcome were available in 1445 of 1641patients recruited to the $\mathrm{BACH}$ trial.

Study population. This study was approved by the review boards of the enrolling institutions. Patients from 15 centers ( 8 in the United States, 6 in Europe, and 1 in New Zealand) were enrolled from March 2007 to February 2008. Patients reporting shortness of breath as their primary complaint upon presentation to the ED were eligible. Patients under 18 years, unable to provide consent, suffering acute STsegment elevation myocardial infarction or receiving renal hemodialysis were excluded.

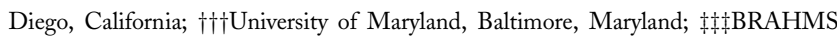
Aktiengesellschaft Biotechnology Centre Hennigsdorf, Berlin, Germany; and the $\S \S \S$ Centre for Clinical and Basic Research IRCCS, San Raffaele, Roma, Italy. Dr. Richards is on the Scientific Advisory Board of Alere; and has received travel support, honoraria, and research grants from Roche Diagnostics and Alere. Dr Maise has received research support from Roche, Biosite, and Bayer; and is a consultant to Alere. Dr. Mueller has received research grants from the Swiss National Science Foundation, the Swiss Heart Foundation, the Novartis Foundation, the Krokus Foundation, Abbott, Biosite, BRAHMS, Roche, and the University of Basel. Dr. Peacock is on the scientific advisory boards of Abbott, Beckman-Coulter, Alere, Ortho Clinical Diagnostics, and Response Biomedical; and has received research grants from Abbott and Alere. Dr. Ponikowski has received honoraria for serving as a consultant for Vifor and Athera; and as a speaker for Merck-Serono, Pfizer, and Sanofi-Aventis. Dr. Filippatos has received research support from Alere, BRAHMS, and Roche. Dr. DiSomma is a consultant to Alere. Dr. Ng is a consultant for Alere and BRAHMS AG. Dr. Daniels has received research support from Alere and Roche Diagnostics. Dr. Neath is a consultant to BRAHMS USA. Dr. Christensen is a consultant for Siemens, BG-Medicine, Critical Care Diagnostics, Alere, and Abbott Diagnostics; and has received research support from Siemens, BG-Medicine, BRAHMS, Roche, Alere, and Nanosphere. Dr. McCord has received research funding from BRAHMS Diagnostics. Mr. Hartmann is an employee of BRAHMS AG, which markets the MR-proANP and MR-proADM assays used in this study. Dr. Anker has received research support from BRAHMS; honoraria from Abbott and Alere; and is a consultant to BRAHMS

Manuscript received October 2, 2012; revised manuscript received February 22, 2013, accepted February 25, 2013.
Confirmation of diagnosis.

Two cardiologists independently reviewed medical records and classified the diagnoses as $\mathrm{HF}$, pneumonia or another cause of dyspnea. They were blinded to each other's assessments, the investigational markers, and the emergency physician's preliminary diagnosis. They had access to the ED case report forms including medical history plus data on chest radiography, radionuclide angiography, echocardiography, and cardiac catheterization as available, as well as the hospital course for those
Abbreviations

and Acronyms

AF = atrial fibrillation

BNP = B-type natriuretic peptide

COPD = chronic obstructive pulmonary disease

$E D=$ emergency department

MR-proANP = mid-region pro-atrial natriuretic peptide

NP = cardiac natriuretic peptide

NT-proBNP = amino terminal pro-B-type natriuretic peptide
HF = acute heart failure who were admitted. In the event of diagnostic disagreement between reviewers they were asked to come to a consensus failing which a third cardiology adjudicator was assigned by the endpoints committee to determine a final diagnosis. All-cause mortality was recorded to 90 days of follow-up.

Measurement of biomarkers. Blood samples were collected into EDTA, and plasma was stored at $-70^{\circ} \mathrm{C}$ in plastic freezer vials. MR-proANP was measured with an automated sandwich chemiluminescence immunoassay on the Kryptor System (BRAHMS AG, Hennigsdorf Berlin, Germany) at the University of Maryland School of Medicine. The assay is described in detail elsewhere (14) and has been used in other studies (16-19). In this laboratory, the MR-proANP assay had a limit of quantitation of $4.5 \mathrm{pmol} / 1$, a within-run imprecision of $1.2 \%$, and total imprecision (CV) of 5.4\%.

BNP was measured with Triage two-site immunoassay reagents (Biosite, San Diego, California) formatted for Beckman Coulter instrumentation (Brea, California). The limit of quantitation was $5.0 \mathrm{ng} / \mathrm{l}$, within-run imprecision was $1.5 \%$, and total imprecision (CV) was $3.0 \%$.

NT-proBNP was measured by electrochemiluminescence with the ElecSys 2010 analyzer (Roche Diagnostics, Indianapolis, Indiana). Limit of quantitation was $10.0 \mathrm{ng} / \mathrm{l}$, within run imprecision $1.5 \%$ and total imprecision $(\mathrm{CV})$ of $3.0 \%$. All samples were processed by personnel blind to patient data.

Statistical analysis. Values are expressed as mean $\pm \mathrm{SD}$, medians and quartiles, or counts and percentages as appropriate. Diagnostic groups were compared with independentsamples t-tests and chi-square tests as appropriate. The discriminative power of each peptide for the diagnosis of $\mathrm{HF}$ was analysed separately for AF and non AF patients by receiver-operator curve (ROC) analyses. Cut points were determined by maximizing the product of sensitivity and specificity. Secondary analyses utilized logistic and Cox regressions and survival curves plotted by the Kaplan-Meier method and compared with log rank tests. Multivariate 
logistic regression analysis was performed to identify variables independently associated with a final diagnosis of $\mathrm{HF}$ including peptides (one in each model), AF, and the covariates age, sex, history of acute HF, myocardial infarction, chronic obstructive pulmonary disease (COPD), diabetes and examination variables (rales, wheezing, third heart sound $\left[\mathrm{S}_{3}\right]$, murmur, edema and elevated jugular venous pressure [JVP]). Multivariate Cox models were used to define variables independently prognostic for mortality and the influence of AF on the prognostic performance of the peptides. Model 1 included the peptide, AF and the interaction term of AF and peptide. Models 2 and 3 additionally included age and sex and age, sex, and creatinine concentration of $>1.6 \mathrm{mg} / \mathrm{dl}$. A p value of $<0.05$ was taken to indicate significance.

\section{Results}

Baseline characteristics. Of the 1,445 patients included in the current analyses, 557 (38.5\%) had HF, and 242 (16.7\%) had AF. AF was more common in those with HF than in those without $(27.5 \%$ and $10 \%$, respectively, $\mathrm{p}<0.001)$. HF was more common in those with AF than in those without (63.2\% and 33.6\%, respectively, $\mathrm{p}<0.001)$. Patient characteristics are presented in Table 1 . Patients with AF were older and more likely to have elevated JVP and rales present on enrollment.

As expected, median BNP, NT-proBNP, and MRproANP values in $\mathrm{HF}$ were significantly higher than in non-HF cases (836 vs. $57 \mathrm{pg} / \mathrm{ml}, 5,171$ vs. $225 \mathrm{pg} / \mathrm{ml}$, and 421 vs. $92 \mathrm{pmol} / 1$, respectively; all $\mathrm{p}<0.001)$. Figure 1 shows plasma concentrations of the 3 peptides in patients with and without $\mathrm{HF}$ further divided according to presence or absence of AF. Lowest values of all three peptides were observed in patients with neither HF nor AF. There was a significant increase in the levels of all 3 peptides in patients with $\mathrm{AF}$ without $\mathrm{HF}$ ( $\mathrm{p}<0.001$ for all 3 peptides $)$ and a further step up in levels in HF with or without AF $(\mathrm{p}<0.001$ for all peptides).

Multivariable analyses indicated each peptide was the strongest independent predictor of a final diagnosis of HF within each model (chi-square values: 138.55 to 171.44 ; $\mathrm{p}<0.0001$ for all) with additional significant predictors consistently including male sex, previous $\mathrm{HF}, \mathrm{COPD}$, diabetes, and presence of rales, edema and raised JVP (Online Tables $1 \mathrm{a}$ to $1 \mathrm{~d})$.

The utility of MR-proANP and the B type peptides for diagnosis of $\mathrm{HF}$ in the presence and absence of $\mathrm{AF}$ was determined by ROC analysis. Figure 2 shows ROC curves for the diagnosis of HF in the absence $(n=1,203)$ and presence $(n=242)$ of AF. In the absence of AF all three peptides exhibited strong and similar discrimination of HF whereas in AF all have similar and substantively lower AUCs. Hence AF resulted in similar clear reductions in the diagnostic power of BNP, NT-proBNP and MR-proANP.
Diagnostic test performance characteristics for ROCderived optimal diagnostic values of all 3 peptides in the presence and absence of AF are displayed in Table 2 for those with and without $\mathrm{AF}$ along with the performance of values currently recommended in clinical practice (i.e., $100 \mathrm{pg} / \mathrm{ml}$ for BNP and age-adjusted values for NTproBNP). The diagnostic performance of optimal values of all 3 peptides in the absence of AF was excellent and very similar with sensitivities exceeding $88 \%$, specificities $>79 \%$, positive predictive values (PPV) $>68 \%$, negative predictive values (NPV) $>92 \%$ and accuracy $>82 \%$. When peptide thresholds derived from the non-AF group were applied to AF patients test performance exhibited preserved sensitivity but marked drops in specificity (from $\sim 80 \%$ down to $30 \%$ ) along with substantively reduced NPV and accuracy (Table 2). When optimum peptide thresholds derived from AF group data were applied to AF patients it was notable that values were higher than those observed for the non- $\mathrm{AF}$ cases and each peptide exhibited major impairment in sensitivity (all $<61 \%)$, NPV $(<53 \%)$ and accuracy $(<67 \%)$ while specificity (all $>73 \%)$ and PPV $(>68 \%)$ were preserved (Table 2).

Natriuretic peptides for prognosis in $\mathrm{HF}$ with and without AF. Ninety-day mortality was 8.6\% (124 of 1,445 patients). Mortality in those with $\mathrm{HF}$ without AF was $11.1 \%$, in those with AF but no HF $11.2 \%$, in those with both, $12.4 \%$ and in those with neither $6.3 \%$. Kaplan-Meier survival curves did not differ between patients with and without AF (data not shown). Over 90 days of follow-up, AUCs for prediction of all-cause mortality in those with HF were of only moderate strength for all 3 peptides and did not differ significantly between absence $(0.65,0.60$, and 0.67 for MR-ANP, BNP, and NT-proBNP, respectively ) and presence of $\mathrm{AF}(0.66,0.62$, and 0.66 , respectively) for any marker. On multivariate analysis there was no significant interaction between $\mathrm{AF}$ and any of the 3 peptide markers for prediction of all-cause mortality (Online Tables $2 \mathrm{a}$ to $2 \mathrm{c}$ ).

\section{Discussion}

Results from the $\mathrm{BACH}$ multinational trial demonstrate that plasma concentrations of MR-proANP, BNP, and NT-proBNP are elevated by AF in the absence of HF. HF is associated with a further increase in peptide levels but, in accord with other recent reports from cohorts with acute breathlessness $(9,10)$ the combination of $\mathrm{AF}$ and $\mathrm{HF}$ was not associated with peptide levels above those seen in HF alone (Fig. 1). This differs from previous reports of smaller cohorts with chronic heart failure in which $\mathrm{HF}$ with $\mathrm{AF}$ was associated with higher plasma natriuretic peptide levels than in $\mathrm{HF}$ alone $(20,21)$. The explanation for this is uncertain but it is likely that in AF with fast heart rate (as is typical in dyspneic AF patients presenting emergently) the onset of acute clinical heart failure occurs at lesser degrees of underlying left ventricular dilatation and dysfunction. That is, increases in peptides due to the specific effects of AF may 


\begin{tabular}{|c|c|c|c|c|c|c|c|}
\hline \multirow[b]{2}{*}{ Variables } & \multirow[b]{2}{*}{$\mathbf{N}$} & \multicolumn{2}{|c|}{ Heart Failure $(n=557)$} & \multirow[b]{2}{*}{ p Value* } & \multicolumn{2}{|c|}{ No Heart Failure $(n=888)$} & \multirow[b]{2}{*}{ p Value* } \\
\hline & & $\begin{array}{l}\text { Atrial Fibrillation } \\
\quad(n=153)\end{array}$ & $\begin{array}{l}\text { No Atrial Fibrillation } \\
(n=404)\end{array}$ & & $\begin{array}{l}\text { Atrial Fibrillation } \\
(\mathbf{n}=\mathbf{8 9})\end{array}$ & $\begin{array}{c}\text { No Atrial Fibrillation } \\
(n=799)\end{array}$ & \\
\hline \multicolumn{8}{|l|}{ Demographics } \\
\hline Age (yrs) & 1,445 & $75.5 \pm 12.1$ & $69.4 \pm 14.1$ & 0.002 & $73.1 \pm 11.71$ & $61.4 \pm 15.8$ & 0.000 \\
\hline No. of males & & 90 & 258 & 0.273 & 49 & 385 & 0.219 \\
\hline \multicolumn{8}{|l|}{ Race } \\
\hline White & 1,019 & 135 & 289 & & 80 & 515 & \\
\hline Black & 361 & 14 & 103 & 0.000 & 8 & 236 & 0.000 \\
\hline Other & 52 & 1 & 38 & & 2 & 11 & \\
\hline \multicolumn{8}{|l|}{ Recent history (\% of entire cohort) } \\
\hline Smoking & 1,402 & 21 & 103 & 0.005 & 15 & 251 & 0.005 \\
\hline Wheezing & 1,353 & 27 & 80 & 0.685 & 17 & 224 & 0.166 \\
\hline Night sweats & 1,313 & 25 & 69 & 0.844 & 16 & 164 & 0.610 \\
\hline Weight gain & 1,256 & 43 & 91 & 0.058 & 9 & 80 & 0.918 \\
\hline Paroxysmal nocturnal dyspnea & 1,316 & 67 & 175 & 0.672 & 24 & 167 & 0.302 \\
\hline Orthopnea & 1,351 & 99 & 238 & 0.101 & 37 & 254 & 0.082 \\
\hline Dyspnea at rest & 1,414 & 78 & 195 & 0.473 & 39 & 371 & 0.578 \\
\hline \multicolumn{8}{|l|}{ History variables } \\
\hline Arrhythmia & 1,369 & 116 & 116 & 0.000 & 64 & 96 & 0.000 \\
\hline Asthma & 1,402 & 6 & 24 & 0.367 & 12 & 173 & 0.065 \\
\hline CRI & 1,389 & 42 & 125 & 0.590 & 9 & 60 & 0.373 \\
\hline Heart failure & 1,402 & 99 & 259 & 0.784 & 31 & 155 & 0.001 \\
\hline Coronary artery disease & 1,393 & 70 & 194 & 0.933 & 29 & 187 & 0.038 \\
\hline COPD/emphysema & 1,399 & 35 & 95 & 0.875 & 33 & 267 & 0.529 \\
\hline Diabetes & 1,426 & 50 & 163 & 0.114 & 21 & 193 & 0.876 \\
\hline Hyperlipidemia & 1,358 & 51 & 182 & 0.025 & 26 & 276 & 0.728 \\
\hline Hypertension & 1,419 & 113 & 316 & 0.425 & 66 & 505 & 0.051 \\
\hline Myocardial infarction & 1,371 & 37 & 130 & 0.073 & 10 & 113 & 0.526 \\
\hline Pulmonary embolism & 1,409 & 18 & 72 & 0.600 & 2 & 44 & 0.195 \\
\hline Prior CABG & 1,421 & 18 & 72 & 0.099 & 6 & 55 & 0.950 \\
\hline Angioplasty/stent & 1,409 & 26 & 80 & 0.539 & 13 & 80 & 0.176 \\
\hline Stroke/CVA & 1,413 & 18 & 55 & 0.581 & 13 & 68 & 0.052 \\
\hline Pacemaker/ICD & 1,421 & 19 & 86 & 0.020 & 9 & 42 & 0.065 \\
\hline Prosthetic valve & 1,417 & 14 & 15 & 0.009 & 3 & 9 & 0.080 \\
\hline \multicolumn{8}{|l|}{ Examination variables (\%) } \\
\hline Mean heart rate (beats/min) & 1,445 & $99.4 \pm 33$ & $85.5 \pm 20$ & 0.0001 & $102.9 \pm 30$ & $91.2 \pm 21$ & 0.0005 \\
\hline Rales & 1,430 & 97 & 203 & 0.009 & 28 & 176 & 0.044 \\
\hline $\mathrm{S}_{3}$ & 1,390 & 6 & 32 & 0.095 & 1 & 5 & 0.587 \\
\hline Murmur & 1,412 & 38 & 118 & 0.311 & 15 & 78 & 0.036 \\
\hline Elevated JVP & 1,351 & 68 & 129 & 0.006 & 12 & 53 & 0.026 \\
\hline Edema & 1,424 & 101 & 237 & 0.194 & 31 & 198 & 0.041 \\
\hline Ascites & 1,393 & 8 & 18 & 0.717 & 1 & 12 & 0.778 \\
\hline Wheezing & 1,424 & 26 & 75 & 0.652 & 24 & 222 & 0.970 \\
\hline
\end{tabular}

Values are $\mathrm{N}$, mean $\pm \mathrm{SD}$, or $\mathrm{n}$. *Comparison of subjects with atrial fibrillation versus without atrial fibrillation, within the subgroups of heart failure diagnosis and no heart failure diagnosis, respectively. $\mathrm{CABG}=$ coronary artery bypass graft; $\mathrm{COPD}=$ chronic obstructive pulmonary disease; $\mathrm{CRI}=$ chronic renal insufficiency; $\mathrm{CVA}=$ cardiovascular accident $\mathrm{OR}$ cerebrovascular accident; ICD = implantable cardioverter-defibrillator; JVP = jugular venous pressure; $\mathrm{S}_{3}=$ third heart sound.

be offset by relatively less underlying ventricular impairment than present in those with acute HF in the absence of AF. These counterbalancing contributions to plasma peptide levels may then result in similar average plasma peptide concentrations as observed by ourselves and others $(9,10)$. This pattern may be absent in chronic, treated $\operatorname{HF}(20,21)$ in which $\mathrm{AF}$ heart rates are lower than in acute $\mathrm{HF}$. Measures of ventricular function are not available from the $\mathrm{BACH}$ cohort and investigation of this proposition must await further study.
The diagnostic performance of MR-proANP, BNP and NT-proBNP was substantially impaired in patients with AF. Findings are qualitatively consistent with those reported by Knudsen et al from the "Breathing Not Properly" trial which assessed the diagnostic utility of BNP in a very similar population to that recruited in the BACH study (9). Morello et al (10) reported elevated NTpro-BNP levels in $\mathrm{AF}$ without $\mathrm{HF}$, in a subgroup analysis from the PRIDE cohort of 600 dyspneic patients. Knudsen et al reported a fall in AUC for diagnosis of $\mathrm{HF}$ by BNP from 0.91 


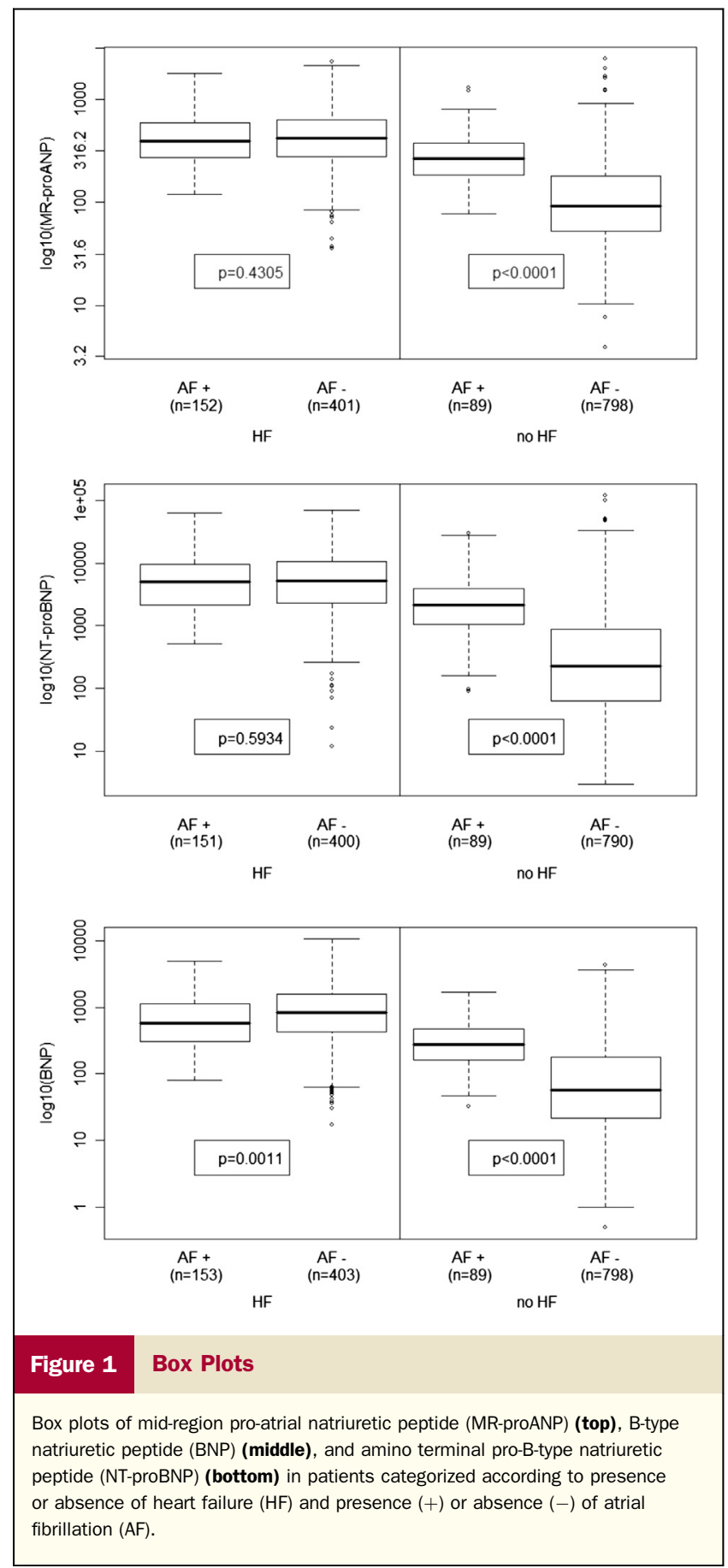

without $\mathrm{AF}$ to 0.84 with $\mathrm{AF}$ (9). In the current report the effect is more pronounced with a change from 0.91 to 0.76 , with very similar results observed for MR-ANP and NTproBNP. It is likely this difference reflects differences in the method used to diagnose AF. In the Knudsen analysis patients with both a medical history of $\mathrm{AF}$ as well as those with $\mathrm{AF}$ on electrocardiogram (ECG) at recruitment were included in analyses as AF patients. However, of 292 patients classified as having permanent or paroxysmal AF, 256 were so classified on the strength of a medical history of AF and of these only 122 presented with ECGdocumented $\mathrm{AF}$ at recruitment in the ED. Therefore about half $(46 \%)$ of patients labeled as "AF" for the purposes of analyses were not in AF at the time of blood sampling. As the effect of the arrhythmia is dynamic with NP levels falling promptly with conversion from AF to sinus rhythm $(11,22-25)$ it is likely this analysis significantly underestimated the extent to which current AF confounds the diagnosis of HF by NPs. The current analysis classifies patients purely according to the rhythm observed on ECG at recruitment.

In $\mathrm{AF}$, loss of atrioventricular synchrony may result in impaired diastolic filling, reduced stroke volume, increased mean diastolic atrial pressure, and reductions in cardiac output (26-28). However, AF also clearly increases plasma levels of NPs in the absence of frank HF (9-13). BNP and NT-proBNP are produced and co-stored in atrial granules along with ANP and amino-terminal ANP (29-31). Rapid $\mathrm{AF}$ with its variable cycle length and ventricular filling times may lead to chaotic microregional variations in atrial cardiomyocyte strain potentially distorting and stretching local populations of cardiomyocytes triggering NP release in the absence of increased mean intra-cardiac or transmural distending pressures (32). Histopathology of atrial tissue in AF reveals inflammatory, hypertrophic and fibrotic changes any and all of which may promote increased NP expression and release (33). This is consistent with the finding of increased pro-BNP and pro-ANP messenger RNA in atrial tissue from patients with AF (34). Together these effects raise plasma NP levels in $\mathrm{AF}$ and weaken their performance in the diagnosis of acute HF.

The ability of physicians to diagnose HF may be impaired in the presence of $\mathrm{AF}$ which can render assessment of physical signs such as jugular venous distension and cardiac sounds more difficult. Therefore the "gold standard" employed to adjudicate the final diagnosis may have been less reliable in AF.

Using peptide thresholds derived from non-AF patients in AF patients results in preserved sensitivity but reduced specificity. Even values optimized for AF cannot match test performance seen in the non AF population (Table 2). However, it is important to note that in the $\mathrm{BACH}$ population (i.e., people presenting with breathlessness to the ED in the absence of an obvious noncardiac cause) two thirds of cases with AF had concurrent HF. In the "Breathing Not Properly" cohort the corresponding figure was $75 \%$ and in "PRIDE" $79 \%$ $(7,10)$. Therefore in patients presenting with acute dyspnea and AF, HF should be presumed present until proven absent as the "false positive" group with elevated NP levels in the absence of HF will comprise only a minority of these patients.

Prognosis. MR-proANP was independently prognostic in the $\mathrm{BACH}$ cohort but did not perform any more strongly than BNP or NT-proBNP and gave weaker 

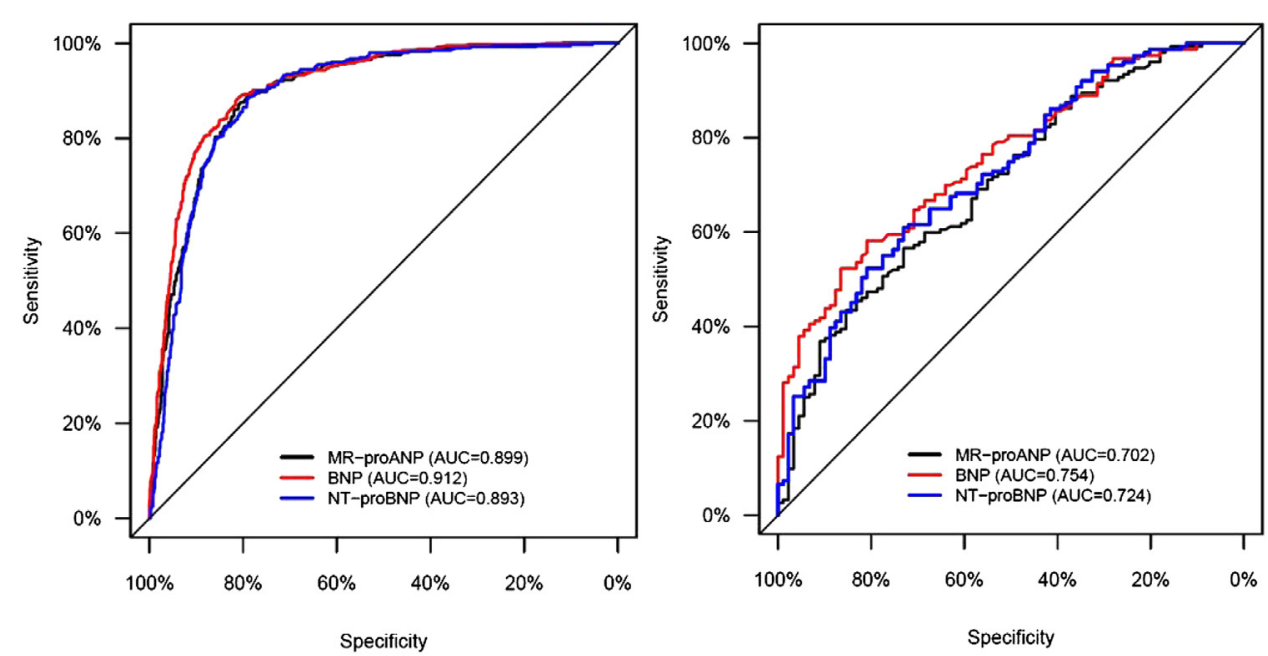

Figure 2 Receiver-Operator Curves for Diagnosis of HF in the Absence $(n=1,203)$ and Presence $(n=242)$ of AF

(Left) Without AF areas under the curve (AUC) were $0.899,0.912$, and 0.893 for MR-proANP, BNP, and NT-proBNP, respectively. (Right) In AF corresponding area under the curves AUCs were $0.702,0.754$, and 0.724 , respectively.

\begin{tabular}{|c|c|c|c|c|c|c|c|}
\hline Cutoff & Sensitivity & Specificity & PPV & NPV & Accuracy & Positive LR & Negative LR \\
\hline \multicolumn{8}{|l|}{ MR-proANP } \\
\hline \multicolumn{8}{|l|}{$\mathrm{AF}$} \\
\hline 210 & 89.5 & 31.5 & 69.0 & 63.6 & 68.0 & 1.31 & 0.33 \\
\hline $370^{*}$ & 56.6 & 73.0 & 78.2 & 49.6 & 62.7 & 2.10 & 0.59 \\
\hline \multicolumn{8}{|l|}{ No AF } \\
\hline $210 *$ & 87.3 & 80.7 & 69.4 & 92.7 & 82.9 & 4.52 & 0.16 \\
\hline 370 & 57.1 & 92.2 & 78.7 & 81.1 & 80.5 & 7.35 & 0.47 \\
\hline \multicolumn{8}{|l|}{ BNP } \\
\hline \multicolumn{8}{|l|}{$\mathrm{AF}$} \\
\hline 100 & 98.7 & 12.4 & 65.9 & 84.6 & 66.9 & 1.13 & 0.11 \\
\hline 220 & 88.9 & 32.6 & 69.4 & 63.0 & 68.2 & 1.32 & 0.34 \\
\hline $490^{*}$ & 58.2 & 80.9 & 84.0 & 52.9 & 66.5 & 3.05 & 0.52 \\
\hline \multicolumn{8}{|l|}{ No $A F$} \\
\hline 100 & 94.3 & 62.7 & 56.0 & 95.6 & 73.3 & 2.53 & 0.09 \\
\hline $220^{*}$ & 88.1 & 81.3 & 70.4 & 93.1 & 83.6 & 4.72 & 0.15 \\
\hline 490 & 71.2 & 92.2 & 82.2 & 86.4 & 85.2 & 9.17 & 0.31 \\
\hline \multicolumn{8}{|l|}{ NT-proBNP } \\
\hline \multicolumn{8}{|l|}{$\mathrm{AF}$} \\
\hline 1,075 & 95.4 & 25.8 & 68.6 & 76.7 & 69.6 & 1.29 & 0.18 \\
\hline $3,460 *$ & 60.9 & 73.0 & 79.3 & 52.4 & 65.4 & 2.26 & 0.53 \\
\hline Age-specific & 88.1 & 32.6 & 68.9 & 61.7 & 67.5 & 1.31 & 0.37 \\
\hline \multicolumn{8}{|l|}{ No AF } \\
\hline $1,075^{\star}$ & 88.5 & 79.0 & 68.1 & 93.1 & 82.2 & 4.21 & 0.15 \\
\hline 3,460 & 64.5 & 90.9 & 78.2 & 83.5 & 82.0 & 7.08 & 0.39 \\
\hline Age-specific & 85.8 & 78.9 & 67.3 & 91.6 & 81.2 & 4.06 & 0.18 \\
\hline
\end{tabular}

Diagnostic test performance with atrial fibrillation (AF) or without (no AF) AF of optimal peptide thresholds (cutoff) derived from AUCs for each peptide separately for AF and non-AF patients. Cutoffs were determined by maximizing the product of sensitivity and specificity. Optimal peptide thresholds in the absence of AF $(n=1,203)$ were 210,220 , and $1075 \mathrm{pg} / \mathrm{ml}$ for MR-proANP, BNP, and NTproBNP, respectively. In AF $(n=242)$, corresponding values were 370,490 , and $3,460 \mathrm{pg} / \mathrm{ml}$, respectively. The test performance of values optimal in AF and no AF are listed for both conditions. Additional values listed for BNP (top row) and NTproBNP (bottom row) are those commonly used in clinical practice (i.e., $100 \mathrm{pg} / \mathrm{ml}$ for $\mathrm{BNP}$ ) and age-specific values for NtproBNp (i.e., $450 \mathrm{pg} / \mathrm{ml}$ for patients $<50$ years of age, $900 \mathrm{pg} / \mathrm{ml}$ for those $>50$ to $<75$ years of age, and 1,800 $\mathrm{pg} / \mathrm{ml}$ for those older than 75 years of age). *Optimal value for the corresponding condition. For MR-proANP and NTproBNP, optimal values for non$\mathrm{AF}$ and AF are listed at the top and in the second row of each panel and in the second and third rows for BNP. LR = likelihood ratio. 
prediction of 90 day mortality than that previously reported for MR-pro adrenomedullin in the $\mathrm{BACH}$ cohort (15). Our findings are consistent with previous reports suggesting the prognostic value of plasma NPs in acute $\mathrm{HF}$ is moderate (i.e., less than their diagnostic power) but is not diminished by AF although the optimal values for prognostic purposes will be higher than that in $\mathrm{HF}$ patients without AF. We detected no interaction between $\mathrm{AF}$ and NPs with respect to prediction of 90-day all-cause mortality.

\section{Conclusions}

MR-proANP has been demonstrated to be non-inferior to BNP and NT-proBNP for the diagnosis of HF in newly breathless patients (15). We report, as in the case of the B-type cardiac natriuretic peptides, the utility of MRproANP for diagnosis of $\mathrm{HF}$ is impaired in the presence of AF. We did not find any significant effect of AF on the prognostic performance of any marker.

These findings indicate the need to consider different (i.e., higher) diagnostic threshold values for natriuretic peptides in the presence of $\mathrm{AF}$ and mandate a continued search for markers which reflect the presence of HF without confounding by AF.

Reprint requests and correspondence: Dr. Mark Richards, University of Otago, Cardioendocrine Research Group, Christchurch School of Medicine and Health Sciences, P O Box 4345, Christchurch, Christchurch NA, New Zealand. E-mail: Mark. Richards@cdhb.health.nz.

\section{REFERENCES}

1. Li H, Easley A, Barrington W, Windle J. Evaluation and management of atrial fibrillation in the emergency department. Emerg Med Clin North Am 1998;16:389-403.

2. Connors S, Dorian P. Management of supraventricular tachycardia in the emergency department. Can J Cardiol 1997;13 Suppl A: 19A-24A.

3. Go AS, Hylek EM, Phillips KA, et al. Prevalence of diagnosed atrial fibrillation in adults: national implications for rhythm management and stroke prevention: the AnTicoagulation and Risk Factors in Atrial Fibrillation (ATRIA) study. JAMA 2001;285: 2370-5.

4. Krahn AD, Manfreda J, Tate RB, Mathewson FA, Cuddy TE. The natural history of atrial fibrillation: incidence, risk factors, and prognosis in the Manitoba Follow-Up Study. Am J Med 1995;98: 476-84.

5. Swedberg K, Olsson LG, Charlesworth A, et al. Prognostic relevance of atrial fibrillation in patients with chronic heart failure on long-term treatment with beta-blockers: results from comet. Eur Heart J 2005;26: 1303-8.

6. Benjamin EJ, Levy D, Vaziri SM, D'Agostino RB, Belanger AJ, Wolf PA. Independent risk factors for atrial fibrillation in a populationbased cohort. The Framingham Heart Study. JAMA 1994;271:840-4.

7. Maisel AS, Krishnaswamy P, Nowak RM, et al. Utility of B-type peptide in the emergency diagnosis of heart failure. N Engl J Med 2002;347:161-7.

8. Januzzi JL, van Kimmenade R, Lainchbury J, et al. NT-proBNP testing for diagnosis and short-term prognosis in acute destabilized heart failure: an international pooled analysis of 1256 patients: The
International Collaborative of NT-proBNP Study. Eur Heart J 2006; 27:330-7.

9. Knudsen CW, Omland T, Clopton P, et al. Impact of atrial fibrillation on the diagnostic performance of B-type natriuretic peptide concentration in dyspneic patients: an analysis from the Breathing Not Properly Multinational Study. J Am Coll Cardiol 2005;46: 838-44.

10. Morello A, Lloyd-Jones DM, Chae CU, et al. Association of atrial fibrillation and amino-terminal pro-brain natriuretic peptide concentrations in dyspneic subjects with and without acute heart failure: results from the ProBNP Investigation of Dyspnea in the Emergency Department (PRIDE) study. Am Heart J 2007;153: 90-7.

11. Lee $\mathrm{SH}$, Jung JH, Choi $\mathrm{SH}$, et al. Determinants of brain natriuretic peptide levels in patients with lone atrial fibrillation. Circ J 2006;70: 100-4.

12. Silvet $\mathrm{H}$, Young-Xu Y, Walleigh $\mathrm{D}$, et al. Brain natriuretic peptide is elevated in outpatients with atrial fibrillation. Am J Cardiol 2003;92: 1124-7.

13. Tsuchida K, Tanabe K. Influence of paroxysmal atrial fibrillation attack on brain natriuretic peptide secretion. J Cardiol 2004;44: $1-11$.

14. Morgenthaler NG, Struck J, Thomas B, Bergmann A. Immunoluminometric assay for the midregion of pro-atrial natriuretic peptide in human plasma. Clin Chem 2004;50:234-6.

15. Maisel A, Mueller C, Nowak R, et al. Mid-region pro-hormone markers for diagnosis and prognosis in acute dyspnea: results from the BACH (Biomarkers in Acute Heart Failure) trial. J Am Coll Cardiol 2010;55:2062-6.

16. von Haehling S, Jankowska EA, Morgenthaler $\mathrm{NG}$, et al. Comparison of midregional pro-atrial natriuretic peptide with $\mathrm{n}$-terminal pro-B-type natriuretic peptide in predicting survival in patients with chronic heart failure. J Am Coll Cardiol 2007;50: 1973-80.

17. Gegenhuber A, Struck J, Poelz W, et al. Midregional pro-A-type natriuretic peptide measurements for diagnosis of acute destabilized heart failure in short-of-breath patients: comparison with B-type natriuretic peptide (BNP) and amino-terminal proBNP. Clin Chem 2006;52:827-31.

18. Gegenhuber A, Struck J, Dieplinger B, et al. Comparative evaluation of B-type natriuretic peptide, mid-regional pro-A-type natriuretic peptide, mid-regional pro-adrenomedullin, and copeptin to predict 1 -year mortality in patients with acute destabilized heart failure. J Card Fail 2007;13:42-9.

19. Khan SQ, O'Brien RJ, Struck J, et al. Prognostic value of midregional pro-adrenomedullin in patients with acute myocardial infarction: the LAMP (Leicester Acute Myocardial Infarction Peptide) study. J Am Coll Cardiol 2007;10:1525-32.

20. Rienstra M, Van gelder IC, Van denBerg MP, Boomsma F, Van Veldhuisen D. Natriuretic peptides in patients with atrial fibrillation and advanced chronic heart failure: determinants and prognostic value of (NT-)ANP and (NT-pro)BNP. Europace 2006;8: 482-7.

21. Corell P, Gustafsson F, Kistorp C, Madsen LH, Schou M, Hildebrandt P. Effect of atrial fibrillation on plasma NT-proBNP in chronic heart failure. Int J Cardiol 2007;117:395-402.

22. Mookherjee S, Anderson G Jr, Smulyan H, Vardan S. Atrial natriuretic peptide response to cardioversion of atrial flutter and fibrillation and role of associated heart failure. Am J Cardiol 1991;67: 377-80.

23. Nishino N, Hoshida S, Tanouchi J, et al. Time to recover from atrial hormonal, mechanical, and electrical dysfunction after successful electrical cardioversion of persistent atrial fibrillation. Am J Cardiol 2000; 85:1451-4.

24. Ohta Y, Shimada T, Yoshitomi H, et al. Drop in plasma brain natriuretic peptide levels after successful direct current cardioversion in chronic atrial fibrillation. Can J Cardiol 2001;17:415-20.

25. Vinch CS, Rashkin J, Logsetty G, et al. Brain natriuretic peptide levels fall rapidly after cardioversion of atrial fibrillation to sinus rhythm. Cardiology 2004;102:188-93.

26. Dries DL, Exner DV, Gersh BJ, Domanski MJ, Waclawiw MA, Stevenson LW. Atrial fibrillation is associated with an increased risk for mortality and heart failure progression in patients with asymptomatic and symptomatic left ventricular systolic dysfunction: 
a retrospective analysis of SOLVD trials. J Am Coll Cardiol 1998;32: 695-703.

27. Van Den Berg MP, Tuinenburg AE, Crïns HJGM, Van Gelder IC, Gosselink ATM, Lie KI. Heart failure and atrial fibrillation: current concepts and controversies. Heart 1997;77:309-13.

28. Naito M, David D, Michelson EL, Schaffenburg M, Dreifus LS. The hemodynamic consequences of cardiac arrhythmias: evaluation of the relative roles of abnormal atrioventricular sequencing, irregularity of ventricular rhythm and atrial fibrillation in a canine model. Am Heart J 1983;106:284-91.

29. Inoue S, Murakami Y, Sano K, et al. Atrium as a source of brain natriuretic polypeptide in patients with atrial fibrillation. J Card Fail 2000;6:92-6.

30. Kambayashi Y, Nakao K, Mukoyama M, et al. Isolation and sequence determination of human brain natriuretic peptide in human atrium. FEBS Lett 1990;259:341-5.

31. Doyama K, Fukuomoto M, Takemura G, et al. Expression and distribution of brain natriuretic peptide in human right atria. J Am Coll Cardiol 1998;32:1832-8.
32. Edwards BS, Zimmerman RS, Schwab TR, Heublein DM, Burnett JC Jr. Atrial stretch, not pressure, is the principal determinant controlling the acute release of atrial natriuretic factor. Circ Res 1988; 62:191-5.

33. Frustaci A, Chimenti C, Bellocci F, et al. Histological substrate of atrial biopsies in patients with lone atrial fibrillation. Circulation 1997;96: 1180-4.

34. Tuinenburg AE, Brundel BJ, Van Gelder IC, et al. Gene expression of the natriuretic peptide system in atrial tissue of patients with paroxysmal and persistent atrial fibrillation. J Cardiovasc Electrophysiol 1999;10:827-35.

Key Words: atrial fibrillation - heart failure - natriuretic peptides.

\section{APPENDIX}

For supplemental tables, please see the online version of this article. 